\title{
Analysis of the loss probability relation on a community level: a contribution to a comprehensive flood risk assessment
}

\author{
M. Huttenlau ${ }^{1}$, K. Schneeberger ${ }^{1,2}$, B. Winter ${ }^{1,2}$, J. Reiss ${ }^{1,2}$ \\ \& J. Stötter ${ }^{1,2}$ \\ ${ }^{1}$ alpS, Centre for Climate Change Adaptation, Austria \\ ${ }^{2}$ Institute of Geography, University of Innsbruck, Austria
}

\begin{abstract}
Flood risk management is an appropriate method to understand and mitigate the consequences of flooding which regularly causes significant losses to property and human lives. Therefore, the analysis of flood risk is a key issue. Within this risk analysis, direct tangible damages are important flood hazard impact indicators. This paper shows an approach of how to assess the potential direct monetary damages in a mountain meso-scale study area (Austrian Province of Vorarlberg). The approach comprises the following key components: (i) asset pooling and its monetary assessment, (ii) exposure analysis, and (iii) susceptibility analysis. By applying this method, loss probability relations reflecting the potential direct monetary damages of flood events with a return period of $30 \mathrm{yrs}, 100 \mathrm{yrs}$ and $300 \mathrm{yrs}$ were derived for all flood exposed communities in the study area. The results illustrate the possible uncertainties that are inherent in the procedure of assessing direct monetary damages. By highlighting this significant variability, it is a valuable contribution to a comprehensive flood risk assessment framework.

Keywords: flood risk, damage functions, asset assessment, direct tangible damages.
\end{abstract}

\section{Introduction and background}

Flood risk analyses are valuable instruments for decision making in risk management. Knowledge about the costs associated with flood events is 
important for a wide range of application fields, e.g. cost-benefit considerations in planning procedures like river training, premium pricing in the insurance industry, calculation of reinsurance coverage, or political decision making (e.g. adequate budget of disaster relief funds).

The general risk concept is based on the understanding of consequences (mostly losses) with a given probability whereby numerous definitions of risk exist $[1,2]$. In this study the definition of the European Flood Directive is followed which defines flood risk as " $[\ldots]$ the combination of the probability of a flood event and the potential adverse consequences for human health, the environment, cultural heritage and economic activity associated with a flood event." [3]. In order to reflect the flood risk situation in a study area adequately, flood risk analysis should (i) consider the whole range of possible scenarios, (ii) relate the scenarios with impact consequences and (iii) carry out a probabilistic risk assessment [4-6].

In the framework of most flood risk analyses, homogenous hazard scenarios with a constant return period (e.g. RP: 100 yrs) throughout an entire river basin are considered. As stated by Thieken et al. [5] the assumption of a constant return period along the relevant river reach or throughout an entire catchment must be questioned, especially for large catchments under study on meso- and macro-scale. To overcome this methodological deficiency the generation of synthetic flood hazard scenarios in combination with flood impact analysis seems to be a promising approach. First studies applying multivariate distribution functions to generate heterogeneous scenarios were recently published $[5,7,8]$.

The Austrian Federal Province of Vorarlberg was affected by serious flood events (e.g. 1999, 2002, and 2005) in the last decades and therefore a thorough flood risk analysis was urgently needed. In strong collaboration with a regional insurance company, a probabilistic flood risk assessment framework was developed for Vorarlberg. This approach has been applied to assess the flood risk of specific insurance portfolio and of the entire assets in the study area. As a conclusion from the discussed drawbacks of using a homogenous scenario in flood risk analysis, this approach is based on heterogeneous scenarios. The framework consists of three major components: (i) a comprehensive flood data catalogue as a surrogate for the analysis of the probability of flooding, (ii) potential flood damages (e.g. direct monetary damages), and (iii) a probabilistic flood risk assessment procedure [9].

Probabilistic risk assessment depends on a large number of flood events/scenarios. Since the number of past damaging flood events is usually relatively small, further events have to be produced synthetically to obtain a comprehensive flood data catalogue. Such events are generated by applying the semi-parametric conditional approach proposed by Heffernan and Tawn [10] which is based on time series derived from river gauging stations. As the approach so far only comprises information on point scale, there is a need for spatial interpolation of all flood events within the comprehensive flood data catalogue to the entire river network. These heterogeneous scenarios comprise information about the flood return period along the entire river network. The 
individual scenarios are combined with loss probability relations which reflect the results of a flood impact study. Subsequently, a synthetic time series of flood losses is generated and statistically evaluated [9].

The presented work focuses on the determination of loss probability relations of communities which are exposed to river floods. The methodology is derived from the frequently applied risk analysis procedure in natural hazard research. The central idea is the application of damage functions to derive the direct monetary flood damages in a study area. In general, the approach of the presented study follows the recommendations of Merz et al. [11] with the main difference being the reordering of the individual steps. Further variations concerning the general methodological framework and the structure of risk-based analysis can be found in the scientific literature [12-14]. All the methodological variations and related studies aim at analysing natural hazard induced consequences assuming a given occurrence probability. In order to achieve this aim, hazard scenarios are systematically combined with socio-economic values. Finally, the consequences of the hazard process on the values are analysed.

This contribution concentrates on assessment of the direct monetary damages on a community level as a major component of the briefly introduced framework for a probabilistic flood risk assessment. As the study has a distinct actuarial background, the contribution focuses on direct tangible damages to buildings and contents (or inventory) based on replacement values. With this contribution specific attention is given to the damage assessment part of the introduced framework. In this manner, we practically overcome the problem that within risk analysis, the damage assessment (compared to the hazard assessment) is often not well balanced (as also emphasised by Merz et al. [11]).

\section{Study area and its flood characteristics}

The study area covers the entire Federal Province of Vorarlberg, Austria with a total area of ca. $2600 \mathrm{~km}^{2}$, of which 21.8 percent are defined as area of permanent settlement (area suitable for building use, transport and agriculture) [15]. Located in the Eastern Alps, Vorarlberg is characterised by a complex mountain topography ranging from $395 \mathrm{~m}$ a.s.l. (Lake Constance) up to $3312 \mathrm{~m}$ a.s.l. (summit of Piz Buin). The main settlement area concentrates on the Rhine Valley (Feldkirch to Bregenz, concentration of two third of the population) and its tributary valley floors, like the valley of the river Ill (Walgau) or the valley of the Bregenzer Ache (Figure 1). Approximately 380,000 people are living in Vorarlberg corresponding to an average population density of 145 inhabitants per $\mathrm{km}^{2}$.

From a hydrological perspective, the major part of the investigated region belongs to the Alpine Rhine basin. The study area can be subdivided into three parts: the flat and densely populated Rhine-Valley, the southern catchment of the river Ill and the catchment of the Bregenzer Ache, a direct tributary to Lake Constance [16].

In the last decades, severe flood events have regularly affected communities in Vorarlberg. As an example, the well documented flood event in 2005 was 
triggered by intensive rainfall over 30 hours with precipitation rates up to $10 \mathrm{~mm} / \mathrm{h}$. Due to high soilwater saturation and the zero degree limit above $2900 \mathrm{~m}$ a.s.l., a high proportion of the precipitation had immediate runoff effects. The overall direct damage in Vorarlberg, covering infrastructure, industries and private property, was estimated to ca. $€ 180$ million [17].

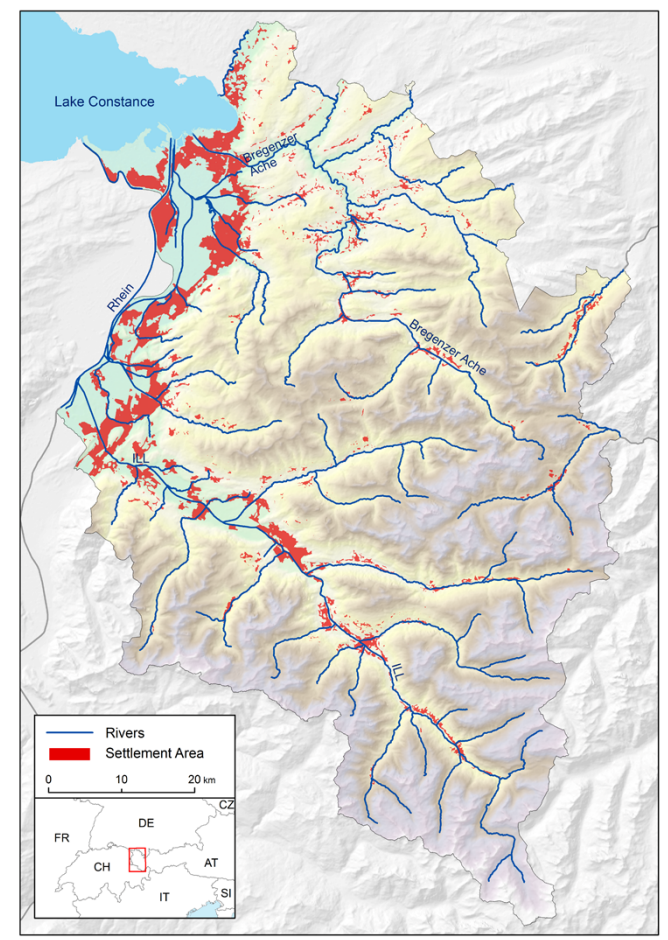

Figure 1: Study area with river network and settlement areas.

\section{Data and methods}

The methodological framework of this assessment of direct monetary flood damages follows the procedure according to Merz et al. [11] with some difference regarding the reordering of individual steps. The assessment comprises the following three steps:

1. Preprocessing: (i) definition and editing of hazard scenarios, and (ii) asset pooling and monetary asset assessment.

2. Exposure analysis: identification of the elements at risk within certain hazard scenarios and assignment of the corresponding hazard impact.

3. Susceptibility analysis: analysis of expected damages by relating damage functions with information of the exposure analysis regarding the elements at risk. 
In research, the third step is often referred to as vulnerability analyses. However, the term 'vulnerability' is used in many risk approaches/concepts of various disciplines (e.g. engineering, geography, sociology or economy), as a consequence, a commonly accepted definition does not exist $[12,14]$. Thus, the authors follow the suggestions of Merz et al. [11] and apply susceptibility analysis as a last step to calculate expected damages.

\subsection{Preprocessing}

The relevant geodata were made available by public authorities (e.g. land surveying office, Vorarlberg). The applied address dataset was made available by the Austrian Post (Österreichische Post AG), all insurance data were made available by Vorarlberger Versicherung $\mathrm{VaG}$.

\subsubsection{Hazard scenarios}

The severe flood event in August 2002 was a trigger for flood risk related research activities in Austria, amongst others the initiation of the national flood mapping project 'HORA' (HOchwasser Risikoflächen Austria - flood risk zones in Austria) [18]. One of the objectives of the HORA project was the generation of inundation maps and their public access as it is also required by the European Flood Directive [3]. A digital elevation model (DEM) with a spatial resolution of $10 \mathrm{~m}$ provided the basis input for (i) the 1-D hydraulic simulation and (ii) the final inundation maps. As the uncertainties associated with this flood maps were considerable, a further development of the model was necessary [19]. Within this improved setup, a DEM with a $1 \mathrm{~m}$ resolution was applied. Additionally, major river reaches with high loss potential were simulated with a 2-D hydraulic simulation. Thus, official inundation maps of good quality approved by a federal authority are available for a return period of $30 \mathrm{yrs}, 100 \mathrm{yrs}$ and $300 \mathrm{yrs}$ for the entire study area.

\subsubsection{Asset pooling and monetary asset assessment}

The study focuses on direct tangible damages to buildings and contents based on replacement values. In a previous research $[6,20]$, it was shown, that portfolio information and derived insured amounts from insurance companies with a high market share in the investigated study area can be very valuable to assess the assets. In contrast to this previous study with a focus on all individual properties of the entire study area, the presented study considers additionally elevation of buildings based on high resolution digital terrain and digital surface models (spatial resolution of $50 \mathrm{~cm}$ ). Thus, mean values of buildings based on cross cubature values can be statistically analysed under consideration of the available insurance portfolio and further extrapolated to the entire building stock.

Therefore, a geodatabase was established which consists of geocoded addresses, building footprints, official land destination plans and building object categories, high resolution aerial images, digital terrain and digital surface models, classified LiDAR point cloud (to derive building footprints), and further data. In a first step, the available insurance portfolio was geocoded (matching rate above 90 percent; the rest lacking correct spatial information). The building 
object categories were combined with the address data and aggregated to six categories (private residential, hospitality industry, office buildings, wholesale and retail sector, industry, and other objects), for which mean values of the insured buildings were statistically analysed on a district level: (i) building cross cubature values for the individual buildings based on the available data (statistical analysis of building footprint and calculated normalized digital surface model) and (ii) mean insured amount per household or content unit. Finally, the derived mean values (indexed to 2013) were extrapolated to the entire building stock in the study area.

\subsection{Exposure analysis}

By means of the exposure analysis the objects which are affected by the hazard process (i.e. flood scenarios) are identified. The hazard scenarios are represented by the inundation maps with a return period of $30 \mathrm{yrs}, 100 \mathrm{yrs}$ and $300 \mathrm{yrs}$. All elements (object based) in the study area were intersected with inundation data. Therefore, the elements at risk associated with the three inundation scenarios were identified including the corresponding water depths.

\subsection{Susceptibility analysis}

The final step to estimate the direct monetary damages is the susceptibility analysis. The concept of damage functions (or susceptibility functions) can be regarded as the central idea, whereas these functions express the susceptibility of the certain types of objects at risk. The damage functions describe the relation between one or more hazard parameters and the relative damage from which the monetary damage can be calculated $[11,21]$.

Table 1: Damage models and key characteristics.

\begin{tabular}{|l|c|c|l|c|}
\hline Name & Origin & Object categories & Content & Example/reference \\
\hline BUWAL & CH & 7 & separate & {$[23,24]$} \\
\hline Damage scanner & NL & 8 & included & {$[25,26]$} \\
\hline Flemish Model & BE & 7 & separate & {$[26]$} \\
\hline FLEMO & DE & 8 & separate & {$[27,28]$} \\
\hline Hübl \& Kraus & AT & 1 & included & {$[24,29]$} \\
\hline IKSE & DE & 5 & included & {$[30]$} \\
\hline JRC & EU & 5 & separate & {$[26]$} \\
\hline MURL & DE & 7 & separate & {$[31]$} \\
\hline Rhine Atlas & DE & 7 & separate & {$[32]$} \\
\hline Romang & CH & 1 & included & {$[24,33]$} \\
\hline Schmidtke & DE & 4 & included & {$[34]$} \\
\hline
\end{tabular}

The most frequently used hazard parameter is water depth, although various other factors, such as flow velocity, duration of inundation, sediment concentration, and contamination of flood water are also relevant [11]. According to the number of influencing parameters damage functions can be differentiated into single- and multi-parameter models. Besides impact 
parameters (e.g. water depth), multi-parameter models often incorporate resistance parameters. Whereas impact parameters depend on the hazard process, resistance parameters are mostly related to the properties of the elements at risk [22]. As they are heterogeneous in space and time, difficult to predict, and limited information exists about their effects, the additional factors of multiparameter models are hardly transferable and thus they are often neglected [11]. Within this study, water depth is the only considered damage parameter.

Besides the damage parameter, the susceptibility functions comprise the different categories of the elements at risk. Damage functions for different object classes based on one methodological development can be referred to as damage model. The flood damage models can be differentiated into empiric and synthetic approaches. Empirical models are derived from damage data collections of ex post event data and synthetic approaches which consider 'what-if-scenarios' [11]. A further distinction into relative and absolute damage function is possible and its implication on a comparative study has to be considered. Table 1 gives an overview about the considered damage models in this study.

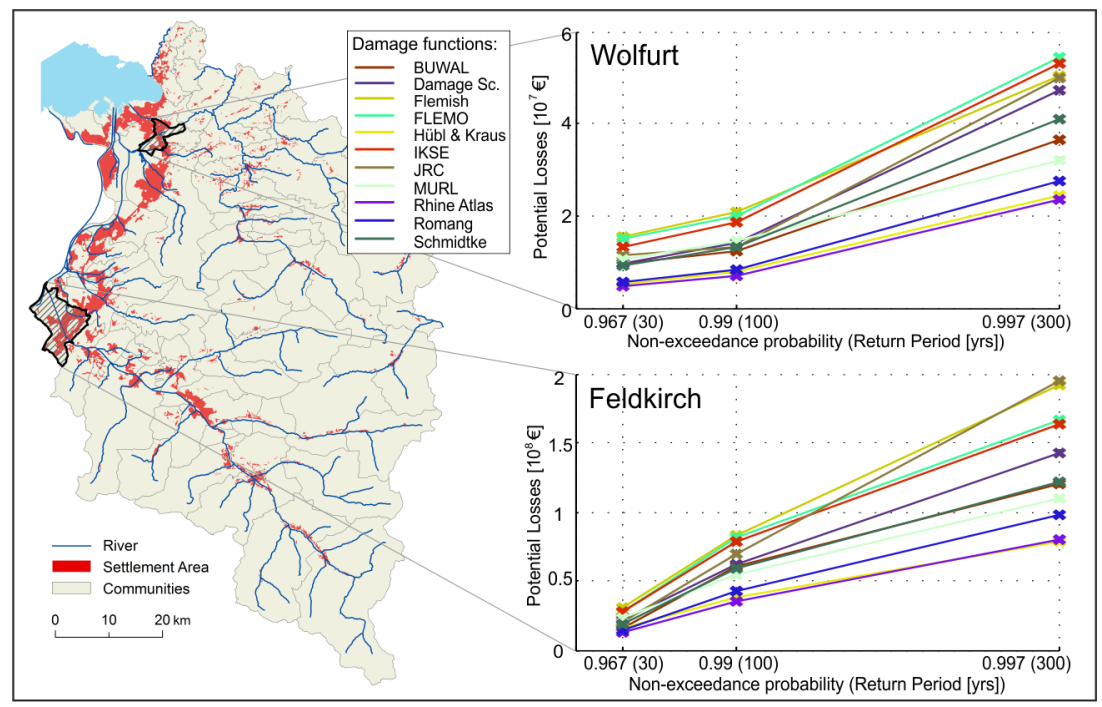

Figure 2: Loss probability relation of two communities and allocation within the study area.

\section{Results}

A procedure for the assessment of tangible direct monetary damages of buildings and contents was applied in the study area Vorarlberg. The loss probability relation for all flood-exposed communities (64 were affected) were calculated considering eleven different damage models (Table 1). These loss probability relations illustrate the maximum potential damages for a return period of $30 \mathrm{yrs}$, $100 \mathrm{yrs}$ and $300 \mathrm{yrs}$ on community level (Figure 2). An accumulation of the 
potential damage of the affected communities leads to a maximum potential direct damage in the study area (Figure 3).

The results of the different damage models differ significantly; for instance the potential damage of the damage model which leads to the highest losses (i.e. FLEMO) is $175 \%$ higher compared to the lowest one (i.e. Rhine Atlas) (RP: $100 \mathrm{yrs}$ ). Figure 3 also illustrates that the potential damage of the model which leads to the highest losses for a RP of 30 yrs is almost the same as the losses associated with the lowest model for a RP of $300 \mathrm{yrs}$. The loss probability relations reflect the maximum possible direct damages associated with different damage models which can occur (triggered by river floods) in each community (exemplarily shown in Figure 2) and the entire study area (Figure 3), respectively.

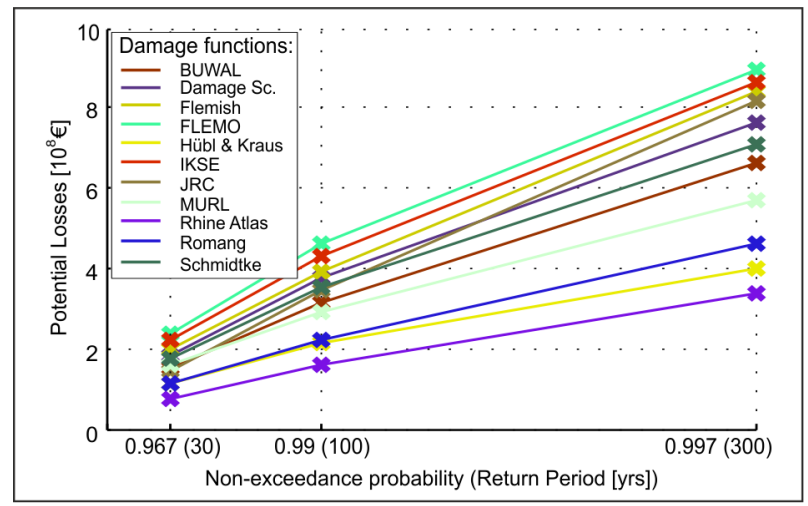

Figure 3: Accumulated loss probability relation of Vorarlberg.

\section{Discussion and outlook}

The assessment of the tangible direct monetary flood damage as a possible flood hazard impact indicator poses an essential component within a probabilistic flood risk assessment framework. As the loss probability relations, have a linear effect on the final framework results, the consideration of one single damage model might lead to significant under- or overestimation of the monetary flood risk. In order to reveal the possible uncertainties, the procedure to assess the direct monetary damages has to be thoroughly examined. The following components are most important:

- Hazard scenarios represented by the flood inundation maps which rely on consistent information regarding the floodplain geometry are of high importance [35].

- Uncertainties related to asset pooling and monetary asset assessment are linked to two key issues. First, pooling has to match the different categories of all damage function, which leads to best match assumptions. Second, extrapolation of mean values to the entire building stock is most suitable for the large number of residential 
buildings, while for most heterogeneous categories such as trade and industry the results lack a sound statistical basis.

- As the exposure analysis is based on single objects, the associated uncertainties are relatively small. Uncertainties arise mainly from the inundation maps as described above. The potential elements at risk (object based) are accurately represented within a geographical information system and thus compared to widely used area based approaches [26], the uncertainties are small.

- In this study a susceptibility analysis was conducted for eleven damage models. To enable a comparison of different damage models few restrictions have to be made: (i) absolute damage models were not considered and (ii) the water depth was the only damage impact parameter. Figure 3 illustrates that the influence of the different damage models on the loss probability relation are considerable. The loss probability relations on a community level are linearly interpolated between the three concretely modelled return periods (RP: $30 \mathrm{yrs,}$ $100 \mathrm{yrs}$ and $300 \mathrm{yrs}$ ). This simplification does not take into account the possible rapid rise on certain water level thresholds (e.g. due to overtopping of embankments). Finally, it has to be questioned whether damage models are transferable in space and time [21].

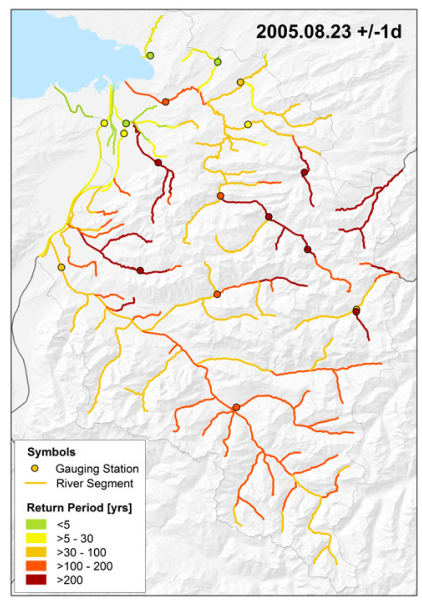

Figure 4: Reconstructed flood event from August 2005 [9].

In general, risk analyses are always associated with considerable uncertainties, which result from the several input parameters involved in the risk analyses procedure and the model itself. It is a common procedure in hydrology (and in other disciplines) to assure a minimum level of quality by comparison of observed and simulated data. This kind of validation would also be desirable in flood risk analysis but as extreme flood events and their adverse consequences can only be seldom observed so far, a traditional validation is hardly possible [5]. Within this study, the monetary damage of eleven different damage models was 
examined, whereas the results differing by the factor of 3 (see Figure 3). A comparison (i.e. plausibilisation) of observed loss data of a local insurance company and of ex post analysis data from public authorities with the model result of the reconstructed flood event 2005 (Figure 4) indicates that the low to moderate damage models deliver the most appropriate results in the study area Vorarlberg.

The loss probability relations provide information about the maximum possible direct monetary damages corresponding to certain recurrence intervals on community level and for the entire study area, respectively. As homogenous flood scenarios (i.e. widespread flooding with constant RP) are very unlikely a probabilistic flood risk assessment framework which considers a wide range of possible flood events is necessary to gather realistic results. Therefore, on the one side a comprehensive data catalogue of flood events is a fundamental surrogate for the probability of flooding, and on the other side the loss probability relations on community level provide information regarding the potential flood damage. These two components can be combined and the resulting time series of flood losses provides the fundamentals for statistical flood risk analysis [9]. Consequently, the loss probability relations are a valuable contribution within the framework of probabilistic flood risk assessment, which is an important feature in the flood risk management cycle.

\section{Acknowledgements}

This work results from the research project InsuRE funded by the Austrian Research Promotion Agency (FFG) within the scope of the programme COMET, the Tyrolean Insurance Company (Tiroler Versicherung), the Vorarlberger Insurance Company (Vorarlberger Landesversicherung). We would like to thank all the institutions that provided data, particularly the Hydrologic Offices and Austrian Post. K.S. acknowledges the financial support provided through the scholarship 'Nachwuchsförderung der Universität Innsbruck'.

\section{References}

[1] Kaplan, S. \& Garrick, B.J., On The Quantitative Definition of Risk. Risk Anal., 1(1), pp. 11-27, 1981.

[2] Paul B.K., Environmental hazards and disasters: Contexts, perspectives and management, Wiley-Blackwell: Chichester, 2011.

[3] EU, European Union on the assessment and management of flood risks: Directive 2007/60/EC of the European Parliament and the Council, 2007.

[4] Merz, B., Elmer, F. \& Thieken, A.H., Significance of "high probability/low damage" versus "low probability/high damage" flood events. Nat. Hazards Earth Syst. Sci., 9(3), pp. 1033-46, 2009.

[5] Thieken, A.H., Apel, H. \& Merz, B., Assessing the probability of largescale flood loss events: a case study for the river Rhine, Germany. J. Flood Risk Manage, 2014. 
[6] Huttenlau, M., Stötter, J. \& Stiefelmeyer, H., Risk-based damage potential and loss estimation of extreme flooding scenarios in the Austrian Federal Province of Tyrol. Nat. Hazards Earth Syst. Sci., 10(12), pp. 2451-73, 2010.

[7] Ghizzoni, T., Roth, G. \& Rudari, R., Multivariate skew-t approach to the design of accumulation risk scenarios for the flooding hazard. Adv. Water Resour., 33(10), pp. 1243-55, 2010.

[8] Keef, C., Tawn, J. \& Svensson, C., Spatial risk assessment for extreme river flows. J Royal Statistical Soc C, 58(5), pp. 601-18, 2009.

[9] Schneeberger, K., Huttenlau, M., Winter, B., Steinberger, T., Achleitner, S. \& Stötter, J., A probabilistic framework for risk analysis of widespread flood events: A proof-of-concept study (in prep.).

[10] Heffernan, J.E. \& Tawn, J.A., A conditional approach for multivariate extreme values (with discussion). J Royal Statistical Soc B, 66(3), pp. 497-546, 2004.

[11] Merz, B., Kreibich, H., Schwarze, R. \& Thieken, A.H., Review article "Assessment of economic flood damage". Nat. Hazards Earth Syst. Sci., 10(8), pp. 1697-724, 2010.

[12] Fuchs, S., Susceptibility versus resilience to mountain hazards in Austria paradigms of vulnerability revisited. Nat. Hazards Earth Syst. Sci., 9(2), pp. 337-52, 2009.

[13] Fuchs, S., Birkmann, J. \& Glade, T., Vulnerability assessment in natural hazard and risk analysis: current approaches and future challenges. Nat Hazards, 64(3), pp. 1969-75, 2012.

[14] Huttenlau, M. \& Stötter, J., The structural vulnerability in the framework of natural hazard risk analyses and the exemplary application for storm loss modelling in Tyrol (Austria). Nat Hazards, 58(2), pp. 705-29, 2011.

[15] Statistik Austria, www.statistik.at/web de/klassifikationen/regionale gliederungen/dauersiedlungsraum.

[16] Schneeberger, K., Huttenlau, M. \& Stötter, J., A Seasonality Analysis of Flood Peaks as Basis for Flood Risk Analyses in two Alpine Regions. Proc. of the $3^{\text {rd }}$ STAHY International Workshop on Statistical Methods for Hydrology and Water Resources Management: Tunis, pp. 1-11, 2012.

[17] Habersack H., Krapesch G., Hochwasser 2005 - Ereignisdokumentation: der Bundeswasserbauverwaltung, des Forsttechnischen Dienstes für Wildbach- und Lawinenverbauung und des Hydrographischen Dienstes, 2006.

[18] Merz, R., Blöschl, G. \& Humer, G., National flood discharge mapping in Austria. Nat Hazards, 46(1), pp. 53-72, 2008.

[19] Amt der Vorarlberger Landesregierung, HORA/Vorarlberg: Hydraulische Neuberechnung für Vorarlberg, 2010.

[20] Huttenlau, M. \& Stötter, J., Ermittlung des monetären Werteinventars als Basis von Analysen naturgefahreninduzierter Risiken in Tirol. Geogr. Helv. (2), pp. 85-93, 2008.

[21] Meyer, V., Becker, N., Markantonis, V., Schwarze, R., van den Bergh, J.C.J.M. \& Bouwer, L.M et al., Review article: Assessing the costs of 
natural hazards - state of the art and knowledge gaps. Nat. Hazards Earth Syst. Sci., 13(5), pp. 1351-73, 2013.

[22] Kreibich, H., Müller, M., Thieken, A.H. \& Merz, B., Flood precaution of companies and their ability to cope with the flood in August 2002 in Saxony, Germany. Water Resour. Res., 43(3), 2007.

[23] BUWAL, Risikoanalyse bei gravitativen Naturgefahren: Fallbeispiele und Daten: Bern, 1999.

[24] Oberndorfer S., Fuchs S., Rickenmann D., Andrecs P., Vulnerabilitätsanalyse und monetäre Schadensbewertung von Wildbachereignissen in Österreich: Wien, 2007.

[25] Bubeck P., de Moel, H., Sensitivity analysis of flood damage calculations for the river Rhine, 2010.

[26] Jongman, B., Kreibich, H., Apel, H., Barredo, J.I, Bates, P.D \& Feyen, L. et al., Comparative flood damage model assessment: towards a European approach. Nat. Hazards Earth Syst. Sci., 12(12), pp. 3733-52, 2012.

[27] Thieken, A.H., Olschweski, A., Kreibich, H., Kobsch, S. \& Merz B., Development and evaluation of FLEMOps - a new Flood Loss Estimation Model for the private sector. Flood recovery, innovation and response. Flood recovery, innovation and response, WIT: Southampton, pp. 315-24, 2008.

[28] Kreibich, H., Seifert, I., Merz, B. \& Thieken, A.H., Development of FLEMOcs - a new model for the estimation of flood losses in the commercial sector. Hydrol. Sci. J., 55(8), pp. 1302-14, 2010.

[29] Hübl J., Kraus D., Erweiterungsvorschläge zur Kosten - Nutzen Untersuchung der Wildbach- und Lawinenverbauung: Wien, 2004.

[30] IKSE, Aktionsplan Hochwasserschutz Elbe: Magdeburg, 2003.

[31] MURL, Hochwasserschadenspotentiale am Rhein in NordrheinWestfalen: Düsseldorf, 2000.

[32] IKSR, Atlas der Überschwemmungsgefährdung und möglichen Schäden bei Extremhochwasser am Rhein: Koblenz, 2001.

[33] Romang H., Wirksamkeit und Kosten von Wildbach-Schutzmassnahmen, Geograph. Inst. der Univ. Bern, 2004.

[34] Schmidtke R.F., Sozio-ökonomische Schäden von Hochwasserkatastrophen. Wasserbauliche Mitteilungen der Technischen Hochschule Darmstadt (40), pp. 143-58, 1995.

[35] Romanowicz, R. \& Beven, K., Estimation of flood inundation probabilities as conditioned on event inundation maps. Water Resour. Res., 39(3), 2003. 